\title{
The use of foamed bitumen in the recycling of asphalt pavements
}

\author{
Chra Khalid \\ Geotechnical Engineering Department, Koya University, \\ Kurdistan Region of Iraq
}

\begin{abstract}
The building of roads and their rehabilitation is increasing around the world. This has effects on the environment and economy. The use of a cold asphalt mixture is increasing because it has a low impact on the environment and high performance in the field; also it is more economical. This study was conducted to find the suitable laboratory mixture design for foamed asphalt to produce the high strength and long performance of this type of mixture.

Keywords: foamed bitumen, advantages of foamed bitumen, bitumen properties, foaming potential, aggregate properties.
\end{abstract}

\section{Introduction}

Due to the development of highway construction and traffic increases, much pavement construction is required and many pavements need to be rehabilitated. A lot of materials are required in highway construction such as aggregate and binder, but the natural raw materials are decreasing and at the same time a large amount of waste materials, which is produced from rehabilitated pavements, are present. In the future, it is believed that the amount of waste will increase every year. Reclaimed asphalt pavements that reuse the milled pavement materials, protects the environment and improves sustainable development. Cold recycling and hot recycling are the two main types of reclaimed asphalt pavement usage methods. Cold recycling can refine durability and structural strength according to binder type used. Cold recycling has two major types, which are emulsified bitumen and foamed bitumen. Using recycled material has many advantages such as saving money and natural resources. The cold mix recycling method is one of the most popular recycling methods today; it provides stable pavements at 
40 to $50 \%$ less spending than needed by new construction. Ordinary hot mix asphalt is an excellent material used to design and construct. To reach this level of excellence it is essential to extract all the water from the aggregate by heating which uses a huge amount of energy. Using this amount of energy costs a lot of money and is environmentally unfavourable. Cold-mix technology provides a new way for design and construction of highways.

\section{What is foamed bitumen?}

Foamed bitumen is a mixture of very hot bitumen and water. It is produced by injecting water into hot bitumen $\left(160-180^{\circ} \mathrm{C}\right)$ which is supported by air. The volume of water is between $2-5 \%$ of the volume of bitumen. When the water contacts the hot bitumen, it rapidly changes to steam and the volume of bitumen expands many times. In this stage the foamed bitumen is produced, it contains thousands of bitumen bubbles and then is ready to be mixed with an aggregate [1].

\section{The advantages of foamed bitumen}

1-Moisture capacity of aggregate materials decreases and shear strength increases. Foamed asphalt has strength which is as high as cementitious materials, but it is more flexible and more resistant to fatigue cracking.

2-Foamed bitumen can be used with different types of aggregates. Typically it is used with aggregates that have a small diameter, which pass the $75 \mathrm{~mm}$, (200) sieve.

3-Foamed asphalt needs less binder and water compared with other types of cold mixing, therefore, the cost of transportation and asphalt binder are reduced.

4-Using foamed asphalt mixture results in time saving during construction because it can be compacted and immediately carry traffic.

5-Foamed asphalt does not affect the environment because it does not give off any volatiles.

6-Energy preservation, only the bitumen requires heating and the aggregate can be mixed with foamed bitumen without drying it, even if the aggregate is damp and cold.

7-Foamed asphalt can be stored for long periods of time without binder runoff or leaching and it remains workable.

8-Weather conditions such as slight rain or cold weather does not affect the quality and workability of foamed asphalt, foamed asphalt layers can be constructing under any weather conditions [2]. 


\section{Laboratory mixture design for foamed asphalt}

In 1988, the Asphalt Institute proposed the following factors that should be taken into consideration. When designing a foamed asphalt mixture, the aggregate gradation and an amount of bitumen should be mixed economically to give the following mixture properties:

1-The amount of bitumen is required to guarantee an appropriate level of resistance and durability for fatigue cracking.

2-To resist deformation by traffic loading, the mixture stiffness and stability should be taken into consideration.

3-The percentage of voids in the mixture is to allow compaction under traffic loading without any of loss of stability or bleeding.

4-Improved moisture susceptibility during mixing, placement and compaction.

\section{Mixture design considerations:}

\subsection{Bitumen properties}

Foamed bitumen is known as expanded bitumen. It is a hot bitumen binder which is transformed from a liquid state to a foam state, when a small water percentage (2\%) is added. The foamed bitumen in terms of expansion ratio and half-life are determined. The half-life is the time in seconds between the time when foam reaches the maximum volume and the time it disperses to half its maximum volume. The expansion ratio is the ratio between the maximum volume reached in the foam state and the final binder volume when the foam has dispersed.

\subsubsection{Foaming potential}

The foaming properties of bitumen have an important role in the mixing stage of foamed asphalt production. A maximised expansion ratio and half-life within the mix will give better binder dispersion. Castedo-Franco and Wood [3] found that disregarding the origin or grade, of any bitumen can be used with a suitable combination of nozzle type, air, water and pressure injected into the bitumen.

Nevertheless, Abel [4] found that:

*Foaming ability will decrease if the bitumen contained silicones.

*Bitumen with low viscosity has higher foam ratios and half-life than the bitumen with high viscosity, but using higher viscosity bitumen works better for aggregate coating.

*The foaming ability of bitumen is concentrated by anti-stripping agents.

* At temperatures above $149^{\circ} \mathrm{C}$ acceptable foaming is accomplished. 
According to Brennen et al. [5] the volume of produced foam, the temperature and the quantity of water affect the half-life and expansion ratio. When high temperatures are used for foaming, increasing the quantity of water results in an increasing expansion ratio, but at the same time results in a decreasing half-life. In the laboratory, the foam parameters are affected by the size of the container (Ruckel et al. [6]). Ruckel et al. [6] suggested limits for the half-life at least 20 seconds and for an expansion ratio 8-15 times. It is possible to produce highly expanded foamed bitumen with greater than 60 seconds halflife and expansion ratio greater than 15 times by using surface-active additives (Maccarrone et al. [7]).

According to Bowering and Martin [8] when foamed bitumen with a high expansion ratio (15:1) was used, the cohesion and compressive strength of mixture will be greater. Also, Maccarrone et al. [7] showed that better aggregate coating and mix properties resulted from high expansion ratio foamed bitumen.

\subsubsection{Foamed bitumen content}

The possible amounts of bitumen content in the foamed asphalt mixture cannot be dictated clearly, but can be fixed in hot-mix asphalt. The binder content range can be fixed by the loss of stability of the mix at the upper end and the water content at the lower end. The ratio of binder content to fines content is the most significant parameter, as the binder fines mixture viscosity has an important role in the stability of the mix. According to table 2, the suitable binder content can be selected based on the fines content of the mix. The use of binder-fines proportion to choose the binder content was suggested by Akeroyd and Hicks [9]. It is in the range from $3.5 \%$ binder content for $5 \%$ fines content to $5 \%$ binder content for $20 \%$ fines content. Probably this process may be not suitable for all types of material, because of the different binder absorbing characteristics of the fines, depending on the material source.

Table 1: $\quad$ Foamed bitumen content (Ruckel et al. [10]).

\begin{tabular}{|l|c|c|}
\hline \% passing $4,75 \mathrm{~mm}$ sieve & \% passing 0,075 mm sieve & \% Foamed bitumen \\
\hline$<50$ (gravels) & $3-5$ & 3 \\
\hline & $5-7,5$ & 3,5 \\
\hline & $7,5-10$ & 4 \\
\hline \hline$>50$ (sands) & $>10$ & 4,5 \\
\hline & $3-5$ & 3,5 \\
\hline & $5-7,5$ & 4 \\
\hline & $7,5-10$ & 4,5 \\
\hline & $>10$ & 5 \\
\hline
\end{tabular}




\subsection{Aggregate properties}

According to the research, many types of aggregates can be used with foamed bitumen, which may range from crushed stone to silty sands. However, specific types of soil need lime treatment and grading modification to be able to be used as shown in Table 1. Figure 7 presents the Mobil foam stabilisation grading from Akeroyd and Hicks [9]. From the chart materials from Zone A will be appropriate for foam treatment and can be used for heavy traffic roads. Also the materials from Zone B are convenient for light traffic roads, but by treating them with coarse fractions they could be adjusted to Zone A. Materials from Zone C are insufficient in fines and they are not suitable for foam stabilisation. An important consideration for the aggregates is the fines content and it is preferred to be more than $5 \%$ by mass (Ruckel et al. [10]).

The mortar which is the mix of bitumen and fines has higher viscosity than the raw bitumen and performs as a mortar between coarse aggregate and increases mix strength. The bitumen content and fines content relationship is critical because bitumen excess in the mortar will work as a lubricant and cause a loss of stability and strength. Foamed asphalt which has high percentages of fines has a higher stability according to Sakr and Manke [11]. Also Bissada [12] presented identical results for tensile strength. The stability of foamed asphalt mixture shown by Sakr and Manke [11] is affected more by the aggregate overlap than by binder viscosity. This is different from what is formed in hot mix

Imperial Sieve Sizes

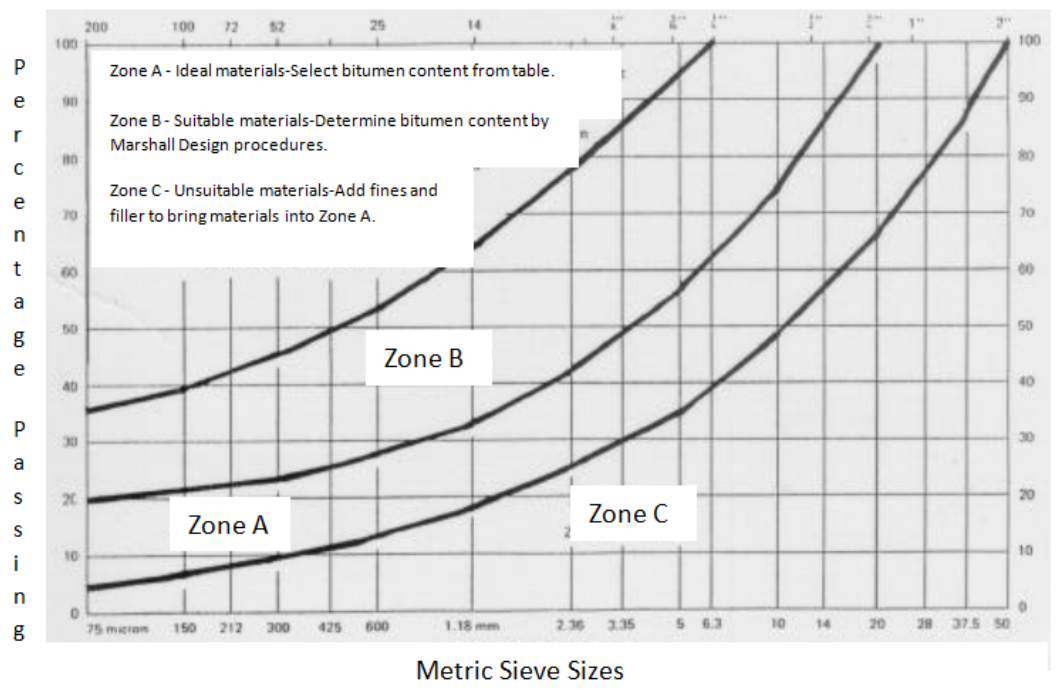

Figure 1: Aggregate grading zones for foamed asphalt (Akeroyd and Hicks [9]). 
asphalt. This means that foamed asphalt mixtures are not affected by temperature as much as hot mix asphalt. Also Sakr and Manke [11] found that fine aggregate angularity is good for foam stabilisation suitability.

\subsection{Moisture content}

Many researchers considered that moisture content is the most important design factor for foamed asphalt mixture during mixing and compaction. Moisture is a pre-requisite for aggregates to soften and break down conglomerates, to support bitumen spreading during mixing and field compaction. A relationship between moisture and density was suggested by Ruckel et al. [10] that will be considered in the formulation of trial mixes. A water deficiency decreases the mix workability and causes imperfect spreading of the binder, however increases in water result in longer curing times, reduces density and the strength of the compacted mix and also reduces the ability for coating aggregates. Depending on the mixture property, the optimum moisture content (OMC) is different, and is optimised by density, water absorption, strength and swelling. These processes during optimising the moisture content should be considered, since moisture for mixing and compaction is critical. Verification by Mobil Oil Australia showed that the optimum moisture content of the aggregate is located at the "fluff point", i.e. the moisture content at which the aggregates have a maximum bulk volume when loose (70-80\% modified AASHTO OMC). Nevertheless, to ensure perfect mixing and compaction, the fluff point particularly for fine materials may be too low. The optimum moisture content of the mixture established by Lee [13] is in the range $65-85 \%$ of the modified AASHTO OMC for the aggregates. This optimum moisture content range was consistent with Bissada [12].

\subsection{Curing conditions}

Curing is the process that foamed asphalt mixture after compaction loses a large percentage of mix moisture, so that the foamed asphalt can develop its strength. Ruckel et al. [6] showed that during the curing process, moisture content had a major effect on the mixture strength, but Lee [13] by experiment showed that in foamed asphalt mixture, loss of moisture is not a precondition for obtaining strength. Whatever the case, a laboratory mix design procedure would be required to simulate the field curing process to form a relationship between the properties of mixes which are prepared in laboratory and those from the field. The curing of foamed bitumen mixture happens over several months in the field, it cannot be implemented to acquire the effective field curing conditions in the laboratory. Bowering [14] suggested a laboratory curing procedure that most previous investigations used i.e. 3 days oven curing at a temperature of $60^{\circ} \mathrm{C}$. 0 to $4 \%$ moisture content is the consequence of this procedure, that is present the driest state accomplished in the field (Muthen [2]). 


\subsection{Temperature conditions}

Depending on the aggregate type, the perfect temperature for aggregate mixing for foamed bitumen ranges from $13^{\circ} \mathrm{C}$ to $23^{\circ} \mathrm{C}$. Temperatures under this range result in a poor quality mixture. Also heated aggregate can be used for preparing foamed asphalt mixes, which increases the binder spreading in the mix and results in coating the large aggregates.

\subsection{Engineering properties}

All studies, which have been done before, show that strength parameters such as Resilient Modulus, stability and CBR at specific intermediate binder content are improved. To design the binder content, the common method used was to improve Marshall Stability and minimise stability loss under soaked moisture conditions. The main functions of foamed bitumen treatment are to decrease the moisture susceptibility, to increase fatigue resistance and to increase the cohesion of the untreated aggregate to adequate levels.

\subsubsection{Fatigue resistance}

The most common distress in road pavement is fatigue. This causes shortening of the pavement's life and increases maintenance and road user cost. This distress manifests itself in the form of cracking and it is associated with pavement thickness and repetitive traffic loading. Fatigue cracks start in the form of micro cracks and proceed to macro cracks. As a result of shear and tensile stresses in road pavements, these cracks expand. Different properties of mixture such as: the amount of binder content in the mixture, type of mixture, air voids and temperature affect the fatigue life of the pavement. It has been determined that aggregate gradation has a significant effect on fatigue resistance more than the effect of bitumen content in the asphalt mixture. For determining the structural capacity of foamed bitumen, pavement layers fatigue resistance is a significant factor. The mechanical characteristics of foamed bitumen mixture are located between granular structure and cemented structure. Bissada [12] showed that fatigue characteristics of foamed asphalt bitumen will be different to those of hot $\operatorname{mix}$

\subsubsection{Moisture susceptibility}

The properties of foamed bitumen strength are dependent on moisture, because of the low binder contents and high void contents of foamed bitumen mixture. Castedo-Franco and Wood [3] discovered that moisture susceptibility of the mixture is decreased by using additives such as lime. Lewis [15] found that cement also can be used to reduce moisture content as it is cheaper than lime. Furthermore high bitumen content decreases the moisture susceptibility because of higher densities leading to lower permeability and increasing the coating of the moist fines with binder. 


\subsection{Additives}

Asphalt pavement distress can be caused by moisture damage or stripping that is recognised as the loss of bond between binder and aggregate. Stripping of asphalt mixture can be an underlying cause of ravelling and cracking. All the cases of stripping are caused by the presence of water. Most anti-stripping additives used are hydrated lime and liquid chemical additives. When these antistripping additives are added to asphalt, they displace the moisture on the aggregate surface and increase adhesion of the binder to the aggregate.

The aim of using additives with foamed bitumen is to achieve good binding of particles to increase strength and make materials more water resistant. Hydrated lime has been used in asphalt from the very beginning. It is mainly calcium hydroxide $\left(\mathrm{Ca}(\mathrm{OH})_{2}\right)$. Generally hydrated lime comes in the form of a dry white powder. Hydrated lime has the following effects on asphalt mixtures properties:

- Gives resistance to moisture damage.

- Gives resistance to chemical ageing.

- Improves mechanical properties such as: modulus, strength, rutting resistance.

Liquid anti-stripping agents are chemical compounds that typically contain amines. Amine based liquid additives, are added to asphalt binders to improve the adhesion between the asphalt binders and aggregate. Most anti stripping agents reduce the surface tension between the bituminous binder and aggregate. Adhesion of binder to the aggregate is promoted when surface tension is reduced. Thus, most liquid anti-stripping agents are surface active agents, Selvamoha et al. [16].

\subsubsection{Temperature susceptibility}

Foamed bitumen mixture is not like hot mix bitumen in terms of temperature susceptibility, although the tensile strength and modulus of the former decreases when temperature increases. After 21 days curing at ambient temperature, foamed bitumen mixture had higher modulus than equivalent hot mix asphalt at temperatures greater than $30^{\circ} \mathrm{C}$. The larger aggregates in foamed bitumen are not coated with binder, so the friction between the aggregates is retained at high temperatures. Nevertheless, bitumen-fines viscosity and stability will reduce at higher temperatures, thus result in strength loss.

\section{Summary and conclusion}

It is essential to have a proper procedure for the mix design for all bituminous mixes, but for foamed bitumen mixture, it can be accomplished by a simple test procedure.

A lot of factors affect the performance and behaviour of foamed bitumen mixtures and all these factors should be taken into consideration when designing. From the literature, it can be seen that, with the development of highway design 
and rehabilitation, lots of waste is produced from using asphalt mixture. This waste is environmentally unfavourable and reuse of this waste is important. Foamed bitumen cold recycling can be used as the solution for this problem. Foamed bitumen cold mixtures have achieved popularity because of their excellent performance and enabling the use of a wide range of aggregate types. Also, it can act as a flexible layer with high water susceptibility. Every year in Koya city a lot of roads rehabilitated. This is result producing large amount of waste and losing money. In view of this, the idea of the "use of foamed bitumen in recycling of asphalt pavements”, can apply for roads in Koya city to make some improvements in these roads.

\section{References}

[1] Thom, N., Principles of Pavement engineering. London: Thomas Telford Ltd., 2008.

[2] Muthen, K., Foamed Asphalt Mixes, Mix Design Procedure, South Africa: CSIR Transportek, 1998.

[3] Castedo-Franco, L., and Wood, L., Stabilisation with Foamed Asphalt of Aggregate Commonly Used in Low Volume Road, Washington, pp. 297302, 1983.

[4] Abel, F., Foamed Asphalt Base Stabilization. Proc. 6th Annual Asphalt Paving Seminar, Colorado State Univ., 1978.

[5] Brennen, M., Tia, M., Altschaeffl, A., and Wood, L., Laboratory investigation of the use of foamed asphalt for recycled bitumenous pavements, Washington, pp. 80-87, 1983.

[6] Ruckel, P., Acott, S., and Bowering, R., Foamed asphalt paving mixtures: Preparation of design mixes and treatment of test specimens. Transportation Research Record , pp. 88-95, 1983.

[7] Maccarrone, S., Holleran, G., \& Ky, A., Cold Asphalt Systems as an Alternative to Hot Mix, 1995.

[8] Bowering, R., and Martin, C., Fomed bitumen production of mixtures evaluation and performance of pavements. Proceedings of the Association of Asphalt Paving Technologists, pp. 453-477, 1976.

[9] Akeroyd, F., and Hicks, B., Foamed Bitumen Road Recycling. Highways, pp. 42-45, 1988.

[10] Ruckel, P., Acott, S., and Bowering, R., Foamed-asphalt paving mixtures: preparation of design mixes and treatment of test specimens. Transportation Research Board, pp. 88-95, 1982.

[11] Sakr, H., and Manke, P., Innovations in Oklahoma Foamix Design Procedures., Washington, pp. 26-34,1985.

[12] Bissada, A., Structural Response of Foamed-Asphalt-Sand Mixtures in Hot Environments, Washington, pp. 134-149, 1987.

[13] Lee, D., Treating Lowa's marginal aggregates and soil by foamix process, Lowa state University, Ames, 1980.

[14] Bowering, R., Properties and Behaviour of Foamed Bitumen Mixtures for Road Building, Canberra, Autralia, pp. 38-57, 1970. 
272 First International Symposium on Urban Development: Koya as a Case Study

[15] Lewis, T., Personal Discussion. Pretoria. AA Loudon \& Partners Consulting Engineers, 1998.

[16] Selvamohan, S., Zaman, Z., Boyd, D., Alexander, A., and Laguros, J., Laboratory Evaluation of Unmodified and Polymer-Modified Performance-Grade Binders with Anti-Stripping Additives. Engineering, Computing and Architecture, Vol. 1, 2007. 